Paidéia, 2001, 11(20), 27-33

\title{
SENTIDO DA HISTÓRIA E IDENTIDADE PESSOAL E POLÍTICA, NA VISÃO DE PADRE ANTÔNIO VIEIRA ${ }^{1}$
}

\author{
Marina Massimi ${ }^{2}$ \\ FFCLRP-Universidade de São Paulo
}

\begin{abstract}
RESUMO: O objetivo deste trabalho é o estudo das relações entre identidade pessoal e política, tempo e história assim como delineiam-se em algumas obras de Padre Antônio Vieira. Nos detemos sobre textos especialmente significativos no que diz respeito à afirmação das concepções acerca do homem, do tempo e da história. A análise demonstra que, para Vieira e toda a tradição judaico-cristã à qual ele se remete, o sentido da história e a prática política constituem-se em dimensões essenciais da identidade humana. A reciprocidade profunda entre a história e o homem proporciona o reconhecimento de uma identificação do destino histórico pessoal e o da humanidade, de modo que cada um reconhece sua própria existência individual como parte da história da humanidade. Portanto, tempo e fatos históricos não são concebidos como fatores estranhos à interioridade do sujeito, mas como pertencentes à consciência que este tem de si mesmo.
\end{abstract}

Palavras-Chaves: História das Idéias Psicológicas, identidade, História e Cultura, Idéias Psicológicas no Brasil

\section{HISTORY'S MEAN, PERSONAL AND POLITICAL IDENTITY IN THE VIEW OF ANTÔNIO VIEIRA}

\begin{abstract}
The objective of this work is the study of relations between personal and political identity, time and history in the texts of Antonio Vieira, SI. The texts especially important were under selection and analyzed; they refer to the conception of man, of time and history. The analysis show that for Vieira, and for all the Judaic-Christian tradition, the sense of History and political practice are essential dimensions of human identity. The deep reciprocity between History and man produces the recognition of one identification between personal destination and the one of humanity, so each one is able to recognize his own existence as part of humanity history. So, time and historical facts are not conceived as strange factors to individual interiority, but as a part of the conscience man has of himself.
\end{abstract} \section{Brazil \\ Key Words: History of Psychological ideas, Identity, History and Culture, Psychological Ideas in}

O objetivo deste trabalho é o estudo das relações entre sentido da História e identidade (pessoal, social e política) no pensamento e na oratória sagrada de Padre Antônio Vieira.

O ponto de partida da análise será a concepção da História do Futuro. Esperanças de Portugal e Quinto Império do mundo obra elaborada em 1661 pelo Padre Viera, no último período de sua existên-

${ }^{1}$ Artigo recebido para publicação em julho de 2001 ; aceito em março de 2002

2 Endereço para correspondência: Marina Massimi, Depto de Psicologia e Educação, Faculdade de Filosofia, Ciências e Letras de Ribeirão Preto-USP, Av. Bandeirantes, 3900, Monte Alegre, Ribeirão Preto, SP, Cep 14040-901, E-mail mmarina@ffclrp.usp.br cia. Diante das múltiplas derrotas vividas por ele mesmo, pela Companhia e pela nação portuguesa, tendo sido expulso em 1661 do Maranhão,junto com toda a Companhia, após nove anos de presença naquela região, devido a suas lutas contra a escravidão dos índios, o grande jesuíta coloca a realização histórica do destino, individual e coletivo, não mais num projeto histórico, voltado para ao presente, e sim no plano da esperança para o futuro. Concebe desse modo o plano do livro História do Futuro, dedicado ao ideal do Quinto Império, a saber, o Reino de Cristo que dentro em breve se havia de instalar na terra. Um príncipe português - o Encoberto - preconiza- 


\section{Marina Massimi}

do pelas profecias ibéricas (Delumeau, 1997), liquidaria definitivamente os inimigos da fé e conquistaria com grande espanto do mundo inteiro, a Terra Santa.

Com efeito, de modo semelhante ao povo hebreu no Antigo Testamento, no tempo presente outro povo foi chamado a ter a função da profecia tendo sido escolhido e preferido entre as demais nações da terra: o povo português (Pecora, 1994) ${ }^{3}$.

Uma vez realizadas estas façanhas, o Quinto Império não tardaria em vir. Seria este um Reino de mil anos, que havia de abranger todas as raças e todas as culturas, fraternalmente unidas na fé católica e incorporadas num só Império mundial; um reino de paz e de concórdia, um reino de justiça e harmonia, no qual as diferentes nações e culturas haviam de obedecer - de livre vontade - aos dois vigários de Cristo: ao papa de Roma, no plano espiritual, e ao rei de Portugal, no plano temporal. Terminado este período milenar, viria o Anticristo, a luta final e a consumação dos tempos. Quando Vieira escreve este livro em 1661, aproximava-se o ano de 1666, data que ele, como muitos outros pensadores dentro e fora de Portugal, tinham por decisiva na história da humanidade, porque então se manifestariam os primeiros sinais da gloriosa transfiguração do mundo $\left({ }^{4}\right)$. Vieira confere assim ao mito sebastianista do sapateiro de Trancoso, Antônio Bandarra, produto da cultura popular portuguesa, sua expressiva representação no grande teatro da história universal e da cultura ocidental (Pecora, 1995b) ${ }^{5}$.

Na História do Futuro, Vieira reafirma a concepção providencialista (Pecora, 1994) ${ }^{6}$ da história humana: Deus é o verdadeiro Senhor da história e a dirige conforme seus planos - misteriosos aos olhos humanos, mas anunciados pelos profetas. Retomando uma metáfora cara ao Barroco, a do teatro da vida, aplica-a à história:

\footnotetext{
3 Alcir Pecora comenta a respeito que "o progresso da cristandade universal, balizado nos sermões de Antônio Vieira, sobretudo pela confluência do divino e do humano na história, estaria, na verdade, para ele, dependente do avanço dessa nação com especial inclinação para o serviço de Deus no mundo." (p.216).

"Vieira, já no fínal de sua existência (pois morreu em 1697), tornará a expor esta tese no livro Clavis Prophetarum escrito em língua latina. $\checkmark$ "É Vieira o primeiro a dar gênio artístico à ardência visionária e nacionalista de Bandarra."

- "Para Vieira, a questão relevante da história não é a de sinalizar simplesmente o Ser absoluto de Deus, mas sinalizá-lo enquanto Providência divina dirigida ao próprio homem."(p.171).
}

"Este mundo é um teatro, os homens as figuras que nele representam, e a história verdadeira de seus sucessos uma comédia de Deus, traçada e disposta maravilhosamente pelas idades de sua Providência. E assim como o primor e subtileza da arte cômica consiste principalmente naquela suspensão do entendimento e doce enleio dos sentidos com que o enredo os vai levando após si, pendentes sempre de um sucesso para outro sucesso, encobrindo-se de indústria o fim da história, sem que se possa entender onde irá parar, senão quando já vai chegando e se descobre subitamente entre a expectação e o aplauso; assim Deus, soberano autor e governador do mundo, $e$ perfeitíssimo exemplar de toda a natureza e arte, para maior manifestação de sua glória e admiração de sua sabedoria, de tal maneira nos encobre as cousas futuras, ainda quando as manda escrever pelos profetas, que não nos deixa compreender nem alcançar os segredos de seus intentos, para nos ter sempre suspensos na expectação e pendentes de sua Providência." (Vieira, 1983, p. 110)

Para além dos artifícios utilizados pelo Altíssimo Cenógrafo na Divina Comédia da história para manter "suspensos" os espectadores, é verdade que em muitos casos as profecias não se entendem porque simplesmente encobertas por vontade dos homens. Assim é que o homem, para ser profeta, deve ter os olhos abertos e atentos a reconhecer as verdadeiras realidades para além das aparências. Ser profeta é então ser capaz de apreender o verdadeiro sentido do tempo:

"Como se hão-de entender as revelações com os entendimentos e os olhos velados? (...) Se os olhos estão cobertos e escurecidos como véu do afecto ou com a nuvem da paixão; se os cega o amor ou ódio, a inveja ou a lisonja, a vingança ou o interesse, a esperança ou o temor, como se pode entender a verdade da profecia, por muito clara que nela esteja, quando o primeiro intento 
é negá-la ou, quando menos, escurecê-la? As nuvens que Deus põe sobre a profecia, $o$ tempo as gasta e as desfaz, mas os véus que os homens lançam sobre os próprios olhos, só eles os podem tirar, porque eles são os que querem ser cegos." ( $p .111$ )

Por outro lado, a história é um continuo revelar-se do Mistério e é por isto que o transcorrer do tempo é um fator que colabora ao desvelar-se das profecias. Com efeito, conforme assinala Pecora (1994), na perspectiva de Vieira a presença divina se inscreve, dirigida aos homens, dentro dos próprios fatos históricos, sendo esses concebidos como lugares da manifestação de Deus. Por isto,

"Descobrimos hoje mais, porque olhamos de mais alto, e distinguimos melhor, porque vemos de mais perto; e trabalhamos menos, porque achamos os impedimentos tirados. Olhamos de mais alto, porque vimos sobre os passados; vemos de mais perto, porque estamos mais chegados aos futuros; $e$ achamos os impedimentos tirados, porque todos os que cavaram neste tesouro e varreram esta casa, foram tirando impedimentos à vista; e tudo isto por benefício do tempo, ou - para o dizer melhor - por providência do Senhor dos tempos." (p. 112)

$\mathrm{Na}$ visão antropológica do pregador jesuíta, a articulação das relações entre homem, tempo e história, parece ser fator estruturante da personalidade humana. Tal concepção é expressiva da posição cultural própria do assim chamado Barroco luso-brasileiro (Maravall, 1997) ${ }^{7}$ da qual Vieira é herdeiro, porta-voz, transmissor e que ainda hoje pode ser reencontrada na tradição cultural brasileira. Pois, conforme assinala "participa integralmente da forma de um século que não concebe meio de falar a Deus, e de Deus, sem experimentar ou aprender a letra diversa do mundo, tão desfigurada pelos pecados da ocasião quanto impregnada da Graça permanente de

\footnotetext{
${ }^{7}$ Maravall define como Barroco um conceito histórico que compreende os três primeiros quartos do século XVIl e que evidencia elementos de relativa homogeneidade nas mentes e nos comportamentos do homem. Tais elementos, em sua articulação conjunta dentro do contexto político, econômico e social, formam uma realidade única.
}

seu Criador" (Pecora, 1995b, p.VIII),

Nesse âmbito, a visão histórica providencialista acima descrita proporciona a definição da identidade pessoal e política do homem, enquanto profeta. Ao mesmo tempo, o homem, mergulhado no tempo histórico, para realizar plenamente sua identidade ao tornar-se profeta, deve adquirir o verdadeiro conhecimento da realidade, buscando apreender seu sentido presente, mas velado pelo mundo das aparências. Trata-se de viver o desengano - categoria gnosiológica muito importante do pensamento barroco, que consiste na capacidade de desenvolver um olhar para a realidade além do engano das aparências, reconhecendo a presença divina oculta no mundo visível (Pecora, 1994). Para tanto, é preciso possuir "pupilas espirituais" - conforme escreve outro grande pregador português Manuel Bernardes (Hatherly, 1997).

Na mentalidade dos séculos XVI e XVII, a evidência é algo necessário ao conhecimento histórico, conforme afirma o jesuíta Agostino Mascardi em 1636, em sua obra Artes istorica (Jori, 1998). O conteúdo da memória torna-se evidência pela arte retórica de quem escreve a obra histórica. Assim, outro jesuíta e contemporâneo de Vieira, o cientista e historiador Anastasius Kircher, autor de dois tratados históricos e de importantes obras científicas, concebe o conhecimento histórico e a investigação científica de modo análogo: o método para interrogar o fato histórico descobrindo seu significado essencial é o mesmo do cientista que olha para o fenômeno buscando apreender sua natureza. Em ambos casos, tratam-se de diversas formas do mesmo ver (Jori, idem). ${ }^{8}$

Por sua vez, tal posição gnosiológica deriva de uma ontologia inspirada na tradição teológica do catolicismo pós-tridentino. Com efeito, para Vieira, a realidade é sacramento, ou seja, teatro da união entre o divino e o humano, teatro do qual a presença

\footnotetext{
${ }^{*}$ A cultura barroca busca então visualizar o tempo e a história, através de imagens e objetos - sejam eles os instrumentos de medição do tempo (relógios, clepsidras, etc) ou, na arte e iconografia, as metamorfoses que o tempo provoca, a representação dos seus efeitos tornando-se assim "espaço de reflexão não só do visível, mas também do invisível". (Hatherly, 1997, p. 98). Neste contexto, adquire significado, por exemplo, a metáfora tão comum na época da caveira, poeticamente retratada por Antônio Serrão de Castro, poeta português do século XVII, nestes termos: "eu também quando menina fui um sol, fui uma aurora/e se sou caveira agora,/ já fui flor, já fui bonina." (idem,
} 
de Cristo na Eucaristia fornece o modelo. O sacramento torna-se assim a modalidade mais adequada do relacionamento do homem com a realidade, pois inclui ao mesmo tempo o imediato caráter concreto da aparência e a dimensão transcendente que lhe confere seu mais profundo sentido. Nessa perspectiva, típica da cultura barroca, "o material ganha uma insuspeitada densidade sacra, os sucessos e as circunstâncias ganham um estatuto de fenômeno, isto é, tudo o que há e ocorre, assim como passa, sinaliza e revela." (Pecora, 1994, p.112). Desse modo, o que é da ordem do transcendente e do indeterminável toma espécies visíveis e materialmente determinadas imprimindo nelas Sua substância própria. Na matéria esconde-se a presença do imaterial, o terreno torna-se o lugar que oculta e contém o divino. Define-se assim o caráter re-velador da realidade, que vela ao mesmo tempo em que anuncia: a realidade torna-se sinal do além, algo que em si mesmo, sem mediação, não se deixa ver. Ela é cena de uma tensão dramática, onde o claro-escuro da evidência garante o papel soberano da liberdade humana.

Nesse sentido, na concepção vieiriana, o senso da história e a construção da identidade pessoal e política são indissolúveis. Em virtude da ação do tempo, a verificação do transitório remete ao eterno transcendente: "Tudo o que ocorre, assim como passa e desfaz-se, também sinaliza e revela permanência" (Pecora, 2001, p.13). E neste âmbito é que o homem do século XVII busca a consistência de sua identidade, do significado de ser pessoa, ser sociedade, ser povo.

Com efeito, para Vieira, assim como para toda a tradição filosófica aristotélico-tomista que o inspira, o ser pessoa é "o que fui, o que hei-de-ser, o que sou" (Massimi \& Mahfoud, 1999, p. 49). Pois, na visão judaico-cristã, o ser pessoa - cujo fundamento ontológico é dado pelo ato da criação - desenvolve-se ao longo do tempo: o homem é peregrino em busca de seu definitivo ser (Silva \& Massimi, 1997).

$O$ destino final da humana peregrinação tem por desfecho o momento do juízo final, quando o ser do homem assumirá sua última definição. No Sermão da Primeira Dominga do Advento, pregado na capela real no ano de 1550 (Vieira, 1993), ao descrever em tons foscos o aproximar-se do juízo final, declara que naquele momento os homens serão separados inicialmente conforme o estado que ocuparam neste mundo, para depois "se começar a segunda separação, segundo o estado que hão de ter na outra, e que há de durar para sempre."(p.117) Portanto, a identidade-humana realizar-se-á plenamente no fim da história. Todavia, o drama do juízo de Deus sobre a história se decide no presente e não num longínquo e imprevisível futuro.

A ênfase no momento histórico atual é o ponto de partida para a afirmação do ideal de justiça social - ideal este a ser realizado apesar de constantemente traído pelos homens. Com efeito, - e isto há de ser de "grande consolação para aqueles a quem não alcançou a fortuna dos altos nascimentos!", - no Dia do Juízo Deus dará "uma grande satisfação à desigualdade com que nascem os homens, sendo todos da mesma natureza." (p.110). Ocorrerá então o restabelecimento da ordem definitiva e própria do Reino de Deus na terra. De modo que:

\section{"Homens humildes e desprezados do povo, boa nova. Se a natureza ou a fortuna foi escassa convosco no nascimento, sabei que ainda haveis de nascer outra vez, e tão honradamente como quiserdes: então emendareis a natureza, então vos vingareis da fortuna." (p. 110)}

A realização desta ordem final, não depende unicamente da ação de Deus na história, mas também da ação humana, que por sua vez estrutura-se a partir do posicionamento da liberdade (ou livre arbítrio): desse modo, num certo sentido, o homem vem a decidir o lugar que ocupa na história, tendo o poder de modificá-lo. Nossa própria condição final "na nossa mão está, se o quisermos ser." (p.112)

Haverá, em suma, um "segundo nascimento" cujo êxito dependerá da liberdade do homem:

"não se faz agravo na desigualdade do nascer, a quem se deu a eleição de ressuscitar. A ressurreição é um segundo nascimento com alvedrio.":

"O ser bem-nascido, que é uma vaidade que se acaba com a vida, é verdade que o não 


\section{Sentido da História $\mathbf{3 1}$}

pôs Deus na nossa mão; mas o ser bem res. suscitado, que é aquela nobreza que há de durar por toda a eternidade, essa deixou Deus no alvedrio de cada um. No nascimento somos filhos de nossos pais, na ressurreição seremos filhos de nossas obras." ( $p .111$ )

De que modo então o homem pode direcionar sua liberdade para que ela se oriente no tempo, através das ações, em busca da realização de sua identidade? Pelo conhecimento de si mesmo. Pois:

Neste mundo racional do homem, o primeiro móbil de todas as nossas ações é o conhecimento de nós mesmos (...) Todos comumente cuidam, que as obras são filhas do pensamento ou idéias, com que se concebem e conhecem as mesmas obras: eu digo que são filhas do pensamento e da idéia, com que cada um se concebe, e conhece a si mesmo. (Vieira, 1993, p. 607)

As ações humanas são expressões da maneira com que o homem concebe e conhece a si mesmo. Em outras enunciações ele diz:

"o conhecimento de si mesmo, e o conceito que cada um faz de si, é uma força poderosa sobre as próprias ações" (Vieira, 1993, p. 612).

$O$ "espelho perfeito" para o homem conhecer-se a si mesmo é a própria "face de Deus" (Vieira, 1993, p. 625).

E a razão disso é inerente à natureza da alma:

"a razão é porque como a alma é uma imagem perfeitíssima de Deus, só à vista do original se pode conhecer perfeitamente a cópia" (Vieira, 1993, p. 625).

Desse modo, na perspectiva de Vieira, conhecimento de si e conversão coincidem: conhecer-se a si mesmos significa poder viver em conformidade com o próprio ser, esta conformidade sendo possível pela participação do Ser criador, o Ser de Deus. ${ }^{9}$
A conformidade do homem com Deus, o encontro face-a-face onde ele participa da natureza divina sendo-lhe de tal forma revelada sua identidade pessoal verdadeira, acontece diariamente nesta terra pela experiência do sacramento - especialmente o sacramento da eucaristia. È assim que a identidade pessoal do homem possui um caráter sacramental, pois a Eucaristia:

enquanto sacramento, foi instituido para o Senhor estar conosco: enquanto comunhão, foi instituído para estar em nós. (Vieira, 2001, p. 155)

Para Vieira, a comunhão sacramental (pela qual Cristo prometeu no Evangelho que "quem come o meu corpo e bebe o meu sangue, está em mim, e Eu estou nele" João: 6, 57) fundamenta uma dupla união: a primeira, "com a qual Cristo quis unir consigo" a alma individual de cada homem, e a segunda "que nos quis unir conosco", entre a coletividade dos homens e a presença divina que se manifesta no meio dela, cujo efeito é de "estarmos unidos entre nós" (idem, p. 156). Portanto, a comunhão se efetiva na medida em que a experiência individual de união mística com Cristo no sacramento articula-se à identidade coletiva, conforme declara no mesmo sermão:

E que quer dizer communio? Quer dizer communis unio: união comum. De maneira que dando Cristo nome à Comunhão, não lhes pôs o nome da união particular que temos com ele, senão da união comum, que causa entre nós." (idem, p. 157)

Por sua vez, o ser comum entre os homens não tem fundamento fora da união entre Deus e a humanidade em Cristo. È assim que teologia e política estão indissociavelmente associadas no pensamento do jesuíta, bem como de toda a tradição

\footnotetext{
${ }^{y}$ O filósofo jesuíta Francisco Suarez (1548-1617) em suas Disputationes Metaphysicae (1597) define Deus como o ser por essência e as criaturas como seres por participação e por dependência de Deus. O ser das criaturas enquanto criado é participação ou imitação do ser de Deus e, portanto, depende de Deus essencial e intrinsecamente. Neste sentido, a criatura é analogia com o seu Criador ${ }^{1}$ Grifo nosso.
} 
tomista que o fundamenta. E é esta associação entre os homens no corpo místico da Igreja que legitima a criação do Estado cristão. Ao considerarmos nesta perspectiva a extensão da produção intelectual de Vieira, repartida entre sermões, cartas, discursos jurídicos e políticos, obras teológicas, pode-se então afirmar que "não há escrito do jesuíta que não seja político: não sê-lo, para ele, equivaleria a renunciar à prática da caridade cristã, deixar de intervir nas formas da vida social do homem de modo a preparálo para tornar-se pela boa escolha de seu livre-arbítrio, co-autor da providência." (Pecora, 1995b, p. VIII).

Portanto, para Vieira e para toda a tradição judaico-cristã à qual ele se refere, o sentido da história e a prática política constituem-se em dimensões essenciais da identidade humana. A reciprocidade profunda entre a história e o homem proporciona na consciência da pessoa o reconhecimento de uma identificação entre o destino histórico pessoal e o da humanidade, de modo que dentro da história da humanidade ela descobre seu próprio destino individual. É assim que o tempo e os fatos históricos referem-se à própria definição da identidade humana, não sendo fatores estranhos à interioridade do sujeito, mas pelo contrário pertencendo à consciência que este tem de si mesmo. Por outro lado, o ser político é expressão da identidade pessoal humana enquanto estruturalmente aberta para além de si mesma.

A distância entre esta visão do mundo e à de nossa sociedade atual é marcada pelas interpretações iluminista e positivista da história e da política. Essas determinaram a dissociação entre consciência e história, entre indivíduo e polis, que perpassa toda a modernidade (Berdiaev, 1979). A razão iluminista, própria dos séculos XVIII e XIX, separou a si mesma da história a acabou por colocar-se de modo externo aos acontecimentos, pretendendo medi-los e julgá-los a partir de critérios por ela definidos. Desse modo, introduziu-se a divisão entre o objeto (história) e o sujeito do conhecimento histórico, divisão esta que caracteriza o homem da modernidade e a ciência histórica enquanto área do saber. Ao mesmo tempo, o indivíduo e o forum de sua vida pessoal foram separados da coletividade, cada vez mais identificada com as feições anônimas do Estado e da massa.

Por fim, a contribuição de Antônio Vieira não deve ser entendida apenas em termos de história do pensamento. A oratória sagrada, especialmente jesuítica, constituiu-se ao longo da primeira modernidade, como instrumento poderosíssimo de formação da mentalidade e da cultura popular (Prosperi, 1999), persistindo em muitos casos ao longo de toda a assim chamada idade moderna.

Fumaroli (1980), ao avaliar a importância deste movimento cultural afirma:

"Engendrant une masse prodigieuse de discours dans l'Europe catholique et en Amerique Latine, cette rhétorique d' Eglise, dont Charles Borromée avait été le premier patron, et le plus autorisé, a eu le pouvoir de créer des mentalités collectives et de répandre dans les masses une doxa remplaçant ou refaçonnant le folklore; elle a su aussi, auprès de l'élite des capitales, cultiver le goût du langage célébré dans une forme noble et belle, accordée á la majesté divine. (p. 144)

A hipótese árdua e fascinante que desafia os pesquisadores das ciências humanas, é a possibilidade de reencontrar no Brasil de hoje, - para além das já conhecidas e marcantes descontinuidades de sua história cultural - eventuais traços que assinalem a permanência de elos de continuidade com a tradição da qual Vieira foi porta-voz, interprete, transmissor.

\section{Referências Bibliográficas}

Ariès, P.H. (1989). O tempo da história. Rio de Janeiro: Alves.

Berdiaev, N. (1979). El sentido de la historia. Madri: Encuentros.

Delumeau, J. (1997). Mil anos de felicidade. Lisboa: Ed. Terramar.

Fumaroli, M. (1980) L'age de l'eloquence, Rhétorique et res literaria de la Renaissance au seuil de l'époque classique. Genève: Droz.

Jori, G. (1998). Per evidenza. Conoscenza e segni 
nell'etá barocca. Torino: Saggi Marsilio.

Hatherly, A. (1997). O Ladrão cristalino. Aspectos do imaginário barroco. Lisboa: Cosmos.

Maravall, J. (1997). A cultura do Barroco. São Paulo: Edusp.

Massimi, M \& Mahfoud, M. (1999). Diante do Mistério. Psicologia e Senso religioso. São Paulo: Loyola.

Pecora, A. (1994). Teatro do Sacramento. São Pau10: Editora UNICAMP-EDUSP.

Pecora, A. (1995a). O desejado. Em A. Novaes (Org.), O desejo. São Paulo: Companhia das Letras.

Pecora, A. (1995b). Prefácio. Em A.Vieira (Org.), Escritos históricos e políticos. São Paulo: Martins Fontes.

Pecora, A. (2000). Introdução. Sermões: o modelo sacramental. Em A.Vieira (Org.), Sermões (pp. 11-25). São Paulo: Hedra, tomo1.

Pecora, A. (2001). Introdução. A pragmática do mistério. Em A.Vieira (Org.), Sermões (pp. 11-27). São Paulo: Hedra, tomo 2.

Prosperi, A. (1999). America e Apocalisse, e altri saggi. Pisa: Istituti Editoriali e Poligrafici Internazionali.

Silva, P.J.C. \& Massimi, M. (1997). A construção do conhecimento psicológico na obra História do predestinado peregrino e seu irmão Precito (1682) de Alexandre de Gusmão S.J. Revista da Sociedade Brasileira de História da Ciência, 17, 71-80.

Vieira, A. (1983). Livro Anteprimeiro da História do Futuro. Lisboa: Biblioteca Nacional.

Vieira, A. (1993). Sermões, vol. 1, Porto: Lello e Irmão.

Vieira, A. (1993). Sermões, vol. 4, Porto: Lello e Irmão.

Vieira, A. (2001). Sermão do Santíssimo Sacramento, pregado em Santa Engrácia, 1662. Em A. Pecora (Org.), Sermões (pp.155-186). São Paulo: Hedra, vol.2. 